\title{
Redefining Masculinity in Haruki Murakami's Men Without Women
}

\section{OPEN ACCESS}

Volume: 8

Issue: 1

Month: December

Year: 2019

P-ISSN: 2320-2645

E-ISSN: 2582-3531

Received: 02.10.2019

Accepted: 15.11.2019

Published: 01.12.2019

Citation:

Mukherjee, Susmita, and Sumathy K. Swamy.

"Redefining Masculinity in Haruki Murakami's Men Without Women." Shanlax International Journal of English, vol. 8, no. 1,2019 , pp. 67-70.

DOI:

https://doi.org/10.34293/ english.v8i1.852

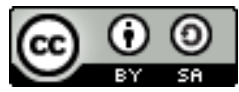

This work is licensed under a Creative Commons AttributionShareAlike 4.0 International License

\author{
Susmita Mukherjee \\ M.Phil. Research Scholar, Krishnammal College for Women, Coimbatore, Tamil Nadu, India
}

\author{
Sumathy K Swamy \\ Associate Professor, Department of English
}

Krishnammal College for Women, Coimbatore, Tamil Nadu, India

\begin{abstract}
For centuries, the concept of the ideal man being macho has dominated all forms of culture. In literature, too male protagonists have been portrayed as strong men who are in control of their emotions. Any form of emotional expression from a man is deemed to be weak and labeled as effeminate. However, contemporary writers like Haruki Murakami are changing how men are portrayed in literature. Murakami makes his male characters vulnerable to pain and sadness, thereby challenging the hegemonic notions of masculinity. The paper focuses on Murakami's collection of short stories titled Men Without Women and studies the male characters in some of these short stories. It attempts to understand the changing definitions of masculinity and probes into what constitutes masculinity.
\end{abstract}

Keywords: Murakami, Masculinity, Feminine, Culture.

\section{Introduction}

The term masculinity has achieved a remarkable eminence in today's cultural landscape. Manliness, till the twentieth century, meant something which is not feminine, something which is more associated with what we can understand as physical strength, denial of luxury, and endurance in the face of death and torment.

Australian sociologist R.W. Connell, in her 1990 book Masculinities has described masculinity as the pattern or configuration of social practices that are linked to the positions of men in the gender order and socially distinguished from practices that are linked to the position of women. Connell further states that masculinities and femininities are best understood as gender projects. The idea that there is an inbuilt plurality in masculinities was first aggressively suggested by R.W. Connell, who said that there are multiple conceptions of masculinity or manliness and as far as the configurations of practice determine there cannot be any single or a unified definition of what constitutes a masculine role in the society.

This concept of plurality, which had started in the feminist thought much earlier, started slightly at a later date in the context of masculinity studies. However, Connell suggests that there is always particular hegemonic masculinity, a particular kind of masculinity that is superior to others at any given moment in every society. In hegemonic masculinity, it is not expected that men would display too many emotions. At the same time, it is expected they be tough and aggressive, avoid any show of vulnerability and display an obsessively sexual behavior with women. Hegemonic masculinity contains within it, the image of a man who is in power. Manhood is being equated as strong, successful, capable, reliable, and in control. 
Japanese writer Haruki Murakami, in his works, overthrows this hegemonic concept of masculinity. One of the most prominent writers of the 20th century, Murakami shot into worldwide fame with his novel Norwegian Wood. Norwegian Wood was a nostalgic tale of love, loss, and sexuality. The story was that of a man looking back on his college days exploring love and sexuality. One of the reasons the novel became extremely popular was because it delved into the male psyche and exposed its insecurities. The protagonist was not a macho man, but a man who was sensitive to emotions could get hurt and struggled with the overwhelming experiences of love and sexuality. The fact that the novel was popular, especially among the youth, implied that people were accepting the mellowed down version of manliness.

Murakami's collection of short stories, Men without Women, initially published in 2014 and translated into English in 2017, yet again reshapes the idea of the conventional masculine man. As the title of the collection suggests, all seven stories in the collection revolve around men who have lost women in their lives. Each story recounts the tale of a man who, for some reason, has lost the love of his life and delves into how each of them reacts and copes with this loss. In doing so, all the protagonists in these stories become vulnerable characters.

\section{The Men in Men without Women}

The first story in the collection is Drive My Car, where the protagonistKafuku befriends the lover of his late wife. As he recollects his relationship with his wife, it is known that he was aware that his wife had had many lovers during their marriage. However, he never confronted his wife on this. Instead, after his wife's death, he strikes a friendship with her last lover, Takatsuki, to discover the reason why his wife had chosen to have these affairs. However, it remains a mystery to Kafuku, and he continues to wonder why his wife had those flings. Kahuku befriends Takatsuki to quench his anger. Kahuku says, "It was slightly different from revenge...As if a demon with nowhere else to go clinging to the corner of the ceiling...I had to get rid of it. To do that, I had to let go of my rage"(18). Thus, Kafuku wanted to punish Takatsuki in his way, "Make him pay for what he did. I planned to put him off his guard by pretending to be his friend, find his fatal flaw, and use it to torture him"(18). However, he doesn't do so. Kahuku realizes that Takatsuki deeply loved his wife. Kahuku tells his chauffeur Misaki, "I can't explain it very well, but at a certain point, a lot of things didn't seem like a big deal anymore... The rage vanished. Or maybe it was never raging in the first place" (19).

In this situation, it is refreshing to see that not once does Kafuku think bitterly of his wife for having these affairs. Neither does he want to be bitter and violent with Takatsuki? Instead, he constantly tries to comprehend the psyche of his wife. Kahuku also doesn't shy away from the fact that he might be feeling insulted or having feelings of jealousy. He admits to Misaki that the actions of his wife had indeed hurt him deeply. However, Kafuku had remained with his wife through her sickness and never projected any toxic behavior.

It is also understood that Kafuku's wife was a more successful actor when they met and married,

"Kafuku was what was generally known as a character actor... Not the leading- man type. His beautiful wife, on the other hand, was a real leading lady, and her roles and income reflected her status. As they grew older, however, he became known as a skilled actor with a distinctive persona, while her star began to wane. But they both respected the other's work, and so the shifts in their popularity and income never caused problems." (8)

The short story begins with Kafuku commenting on women drivers. He says that women drivers can be segregated broadly into two categories- too timid or too aggressive. However, Kafuku's intention is not to stereotype women. He admits that there are neutral female drivers as well as terrible male drivers. Kahuku only highlights the difference in attitude between male and female drivers. He says that women drivers are more cautious in general and remarks, "Of course, that caution was nothing to complain about" (1). Further, the narration states, "Kafuku seldom drew distinctions between men and women in his daily life. Nor was he apt to perceive any difference in ability between the sexes. There were as many women as men in his line of work, and he felt more at ease working with women" (1). 
The second tale, Yesterday, brings out the sexual insecurity of the character Kitaru. Contrary to common representations where the woman is the one shying away from physical intimacy, here it is the man who is averse to physical intimacy. Kitaru says to his friend, "I just couldn't. I've known her since she was a kid, and it's kind of embarrassing, y' know, to act like we're just starting, and take her clothes off...I dunno - it just seems wrong. You know?" (25). He also says that he would perhaps be more comfortable being physical with someone whom he doesn't like much. Kitaru's friend Tanimura and Kitaru's longtime girlfriend Erika are unable to comprehend his attitude towards sex. Nevertheless, Kitaru loves Erika, and perhaps that is the reason why he insists that Tanimura and Erika go out on a date. He wishes that Erika moves on in life with someone who can satisfy her not only emotionally but also physically.

When Erika and Tanimura see each other again after sixteen years, Tanimura learns that Erika and Kitaru are remotely in touch, and Kitaru is unmarried. Yesterday is yet another story that deals with insecurity that men may have with their sexuality. This image of the man contrasts with that of the alpha male who is always extremely confident, upfront, and comfortable with his sexuality.

The rest of the stories are marked with heartbreaks and how it affects men emotionally. The Independent Organ tells the story of a successful cosmetic plastic surgeon Dr. Tokai. He leads what one might term as the ideal bachelor's life. Fifty two and unmarried, Dr. Tokai has had numerous flings all his life, usually with committed or married women. However, he falls in love with a thirtysix-year-old mother. The love is not reciprocated, and the affair ends after she leaves him. Dr. Tokai is heartbroken, becomes anorexic, and eventually dies of starvation. After leading a popular and the so-called ideal life, his tragic death is shocking. His death is a result of emotional repression. Dr. Tokai is unable to deal with heartbreak, and this emotional turbulence results in his death. The story of Dr. Tokai subtly hints as to what emotional repression can do. It is also a comment on the dark side of hegemonic masculinity.
Similarly, other stories in the collection like Kino and Men without Women project men who are struggling to deal with their emotions. They bring out the fact that men can be equally vulnerable to emotions as women are. In Men Without Women, the narrator says,

“And once you've become Men Without Women, loneliness seeps deep down inside your body, like a red - wine stain on a pastel carpet... The stain might fade a bit over time, but it will remain as a stain until the day you draw your final breath...And you are left to live the rest of your life with the gradual spread of that color, with that ambiguous outline." (106)

\section{Conclusion}

From comic strips to superhero cinema, from thrillers and action movies, from romance novels to television, the stereotype of the masculine, dominant, and aggressive male makes recurring appearances and this has had an impact on the way manhood is perceived not only by men but also by women. However, contemporary writers like Murakami are changing those notions and redefining what masculinity is. The men in Men without Women like Kafuku or Dr.Tokai are all successful in their professional lives. Murakami attempts to naturalize the fact that men have emotions, and by discussing these emotions and their insecurities, he attempts to give shape to a culture where it is normal for men to discuss them. Book critic David Zarley remarks, "It's centered on women who are defined via men's perceptions, but it resists the urge to blame the said woman for the pain it presents."

Masculinity thus is not just about immense physical and emotional strength anymore. Excessive aggressiveness is no longer considered as strength but rather categorized as toxic behavior. Instead, their strength lies in the fact that they can probe into their emotional behavior and trying to deal with it with maturity rather than by repression and aggressiveness. 


\section{References}

Connell, RW. Masculinities, University of California, Berkeley, P. 1995.

Fielden, Jay. New From Murakami: Tales of Cool Cars, Shinto Spirits, and Lost Love, The New York Times, New York, 2017.

Kellaway, Kate. Men without Women by Haruki Murakami-Review, The Guardian, London, 2017.

\section{Author Details}

Susmita Mukherjee, M.Phil., Research Scholar, Krishnammal College for Women, Coimbatore, Tamil Nadu, India, Email ID: mesush.95@gmail.com.

Dr. Sumathy K Swamy, Associate Professor, Department of English, Krishnammal College for Women, Coimbatore, Tamil Nadu, India, Email ID: sumathikswamy@psgrkcw.ac.in.
Murakami, Haruki. Men without Women, translated by Philip Gabriel and Ted Goossen, Harvill Secker, London, 2017.

Zarley, David. No Pity: Masculinity and Haruki Murakami's Men Without Women, Paste Magazine, 2017. 